\title{
PERANCANGAN SISTEM INFORMASI PEMESANAN KAMAR HOTEL BERBASIS WEBSITE (WEB) MENGGUNAKAN DATA FLOW DIAGRAM (DFD)
}

\author{
Muliadi $^{1}$, Meri Andriani ${ }^{2}$, Heri Irawan ${ }^{3}$ \\ Program Studi Teknik Industri, Fakultas Teknik, Universitas Samudra \\ Email:1'mteuku303@gmail.com; ${ }^{2}$ meri_tind@unsam.ac.id; ${ }^{3}$ irawan84@unsam.ac.id
}

\begin{abstract}
ABSTRAK
Hotel Kartika Kota Langsa adalah salah satu hotel tertua yang ada di Kota Langsa dan Hotel Kartika masih berstatus bintang 2, hotel ini berdiri pada tahun 1982 yang di dirikan oleh bapak H.Abdullah Hanafiah dan sampai sekarang masih beroperasi dalam melayani pelanggan hotel. Hotel Kartika mempunyai 47 orang tenaga kerja yang terbagi dari beberapa bagian yang sudah terstruktur. Hotel Kartika Kota Langsa memiliki 70 kamar, dengan 52 kamar di lantai 1 dan 18 kamar di lantai 2. Hotel Kartika dalam sehari dapat terisi 25 sampai 35 kamar. Harga kamar Hotel Kartika berkisar antara 150 ribu sampai 800 ribu/kamar. Permasalahan pada Hotel Kartika adalah belum berjalan nya sistem informasi pemesanan kamar hotel secara online, sehingga konsumen (tamu hotel) masih memesan kamar hotel secara langsung. Tujuan dari penelitian ini adalah Merancang sistem informasi pemesanan kamar hotel agar dapat mempermudah konsumen (tamu hotel) dalam memesan kamar hotel secara online yang berbasis website (WEB). Penelitian ini menggunakan metode data flow diagram (DFD) untuk merancang aliran sistem dan bahasa pemrograman menggunakan personal home page (PHP) dalam merancang website (WEB). Hasil dan pembahasan pada perancangan website (WEB) terdapat 2 level proses yang akan berjalan dalam pemesanan kamar hotel secara online yaitu level 1 terdiri dari daftar akun login tamu, login admin, check-in hotel dan cetak struk pemesanan harian, sedangkan untuk level 2 tediri dari login tamu,pesan kamar, pilih tipe kamar, pengisian data pemesanan,pilih jenis bank transaksi, konfirmasi pembayaran, konfirmasi pemesanan, input data tamu,id card kamar hotel, pengolahan laporan harian,bulanan dan tahunan. Kesimpulan dalam penelitian ini adalah Sistem informasi pemesanan kamar hotel yang berbasis website (WEB) ini memudahkan pelanggan untuk mengetahui informasi hotel dan sistem pemesanan kamar pada Hotel Kartika. website (WEB) juga menampilkan data fasilitas hotel, data kamar hotel,data laporan hotel beserta data harga kamar hotel dan tipe kamar hotel secara jelas karena tersedianya database yang baik dalam bentuk file-file komputer. Website yang telah di rancang bisa di kunjungi dengan nama domain hotel-kartika.epizy.com
\end{abstract}

Kata kunci: Sistem informasi hotel, DFD,WEB

\section{ABSTRACT}

Hotel Kartika Langsa City is one of the oldest hotels in Langsa City and Hotel Kartika is still 2-star status, this hotel was founded in 1982 which was founded by Mr. H. Abdullah Hanafiah and is still operating in serving hotel customers. Hotel Kartika has 47 workers who are divided into several structured sections. Hotel Kartika Kota Langsa has 70 rooms, with 52 rooms on the 1st floor and 18 rooms on the 2 nd floor. Hotel Kartika can be filled with 25 to 35 rooms a day. Hotel Kartika room prices range from 150 thousand to 800 thousand / room. The problem at Hotel Kartika is that an online hotel room reservation information system has not been running, so that consumers (hotel guests) still book hotel rooms directly. The purpose of this research is to design a hotel room reservation information system in order to make it easier for consumers (hotel guests) to book hotel rooms online based on a website (WEB). This study uses the data flow diagram (DFD) method to design a system flow and programming language using a personal home page (PHP) in designing a website (WEB). Results and discussion on website design (WEB), there are 2 levels of process that will run in online hotel room reservations, namely level 1 consisting of a list of guest login accounts, admin logins, hotel check-in and printing daily order receipts, while for level 2 there are from guest login, order room, select room type, fill in reservation data, select transaction bank type, payment 
confirmation, order confirmation, guest data input, hotel room id card, daily, monthly and annual report processing. The conclusion in this study is the website-based hotel room reservation information system (WEB) makes it easy for customers to find hotel information and room reservation systems at Hotel Kartika. The website (WEB) also displays hotel facilities data, hotel room data, hotel report data along with hotel room price data and hotel room types clearly because of the availability of a good database in the form of computer files. Website that has been designed can be visited with the domain name hotel-kartika.epizy.com

Keywords: hotel information system, DFD, WEB

\section{PENDAHULUAN}

Hotel Kartika Kota Langsa adalah salah hotel tertua yang ada di Kota Langsa dan Hotel Kartika masih berbintang 2, hotel ini berdiri pada tahun 1982 yang di dirikan oleh bapak H.Abdullah Hanafiah dan sampai sekarang masih beroperasi dalam melayani pelanggan hotel. Hotel Kartika mempunyai 47 orang tenaga kerja yang terbagi dari beberapa bagian yang sudah terstruktur. Hotel Kartika Kota Langsa memiliki 70 kamar, dengan 52 kamar di lantai 1 dan 18 kamar di lantai 2 . Hotel Kartika dalam sehari dapat terisi 25 sampai 35 kamar. Harga kamar Hotel Kartika berkisar antara 150 ribu sampai 800 ribu/kamar.

Dengan adanya perkembangan sistem informasi yang berbasis website (WEB) pada Hotel Kartika akan menjawab berbagai masalah khususnya dalam hal proses reservasi, check in serta check out. Selain itu dengan teknologi tersebut juga akan meningkatkan operasional internal departemen karna data dapat diolah dengan cepat dan akurat sehingga menghasilkan suatu informasi yang tepat bagi pebisnis hotel.

Penelitian terdahulu (Prasetyo, 2015) dengan judul "Sistem Informasi Manajemen Hotel Arrahman Tembilahan Berbasis website (WEB) Pada Hotel Arrahman Tembilahan, Sistem informasi manajemen berbasis website (WEB) pada Hotel Arrrahman Tembilahan merupakan sistem informasi manajemen yang memungkinkan pihak Hotel Arrahman untuk bisa memberikan suatu informasi kamar, data tamu, data inap tamu yang lebih akurat secara online, sehingga bisa memberikan kemudahan bagi pelanggan/ tamu yang memiliki kesibukan yang padat atau berdomisili jauh dari perkotaan dapat megetahui informasi jasa penginapan hotel jika ada urusan pekerjaan dan lainnya dan memerlukan waktu berhari-hari.

Parahita ( 2018) dengan judul "Sistem Informasi Perhotelan Berbasis Web Service : Studi Kasus Di Pulau Lombok. Pulau Lombok memiliki banyak hotel. Hotel biasanya memiliki situs website yang dapat dikunjungi turis untuk memesan atau hanya melihat informasi tentang hotel. Kebutuhan Turis dalam memperoleh informasi hotel yang terletak di pulau Lombok dalam satu situs website (WEB), kemudian situs website (WEB) hotel terintegrasi yang dapat menampung informasi berbagai hotel di Lombok sangat dibutuhkan untuk memenuhi persyaratan ini.

Dari hasil wawancara dengan manajemen Hotel Kartika peneliti tertarik untuk membuat sebuah website (WEB) pemesanan kamar hotel secara online agar proses pemesanan kamar hotel lebih mudah di lakukan, mempermudah dalam membuat laporan harian,bulanan dan harian karna semua database berada dalam sebuah komputer yang sudah di rancang sistem nya dengan struktur yang baik.

\section{TINJAUAN PUSTAKA}

Pengertian Perancangan Sistem Informasi

Adalah suatu tahapan kegiatan yang dilakukan seseorang atau kelompok dalam merancang atau membuat sistem sebelum sistem dibuat, dengan tujuan sistem yang dibangun sesuai dengan kebutuhan dalam memecahkan atau dengan kebutuhan pengguna berkaitan dengan pengolahan, pengelolaan dan perolehan informasi yang diinginkan (Muslihudin,dkk. 2016).

\section{Diagram Konteks}

Diagram konteks merupakan pola penggambaran yang berfungsi untuk 
memperlihatkan interaksi sistem informasi dengan lingkungan dimana sistem tersebut ditempatkan. Gambaran ini tidak tergantung pada perangkat keras, perangkat lunak atau organisasi file. Suatu diagram konteks selalu mengandung satu proses saja (diberi nomor proses 0), menggambarkan hubungan input/output antara sistem dengan dunia luarnya (Kusumawardani, 2014).

\section{Data Flow Diagram (DFD)}

Data flow diagram (DFD) adalah suatu bagan yang menggambarkan arus data dalam suatu perusahaan, yang digambarkan dengan sejumlah simbol tertentu untuk menunjukkan perpindahan data yang terjadi dalam proses suatu sistem bisnis (Surono. 2014).

\section{FlowChart}

Flowchart mendeskripsikan detail sebuah proses, tahapan dan urutannya secara grafis. Flowchart berisi bagan-bagan yang mempunyai arus yangmenggambarkan lagkahlangkah penyelesaian suatu masalah (Astuti.2016).

\section{Website (WEB)}

Sari,dkk (2019) definisi website atau disingkat web adalah sekumpulan halaman yangterdiri dari beberapa laman yang berisi informasi dalam bentuk digital baik itu teks, gambar, animasi yang disediakan melalui jalur internet sehingga dapatdiakses dari seluruh dunia.

\section{Personal Home Page (PHP)}

Menurut Lerdorf (1995) PHP adalah bahasa pemrograman script yang paling banyak dipakai saat ini. Personal Home Page(PHP) banyak dipakai untuk memrogram situs website dinamis, walaupun tidak tertutup kemungkinan untuk digunakan untuk pemakaian lain.

\section{METODE PENELITIAN}

Dalam melakukan pengumpulan data dan informasi penulis menggunakan beberapa metode pengumpulan data, yaitu:

1. Data Primer

Data primer adalah data yang diperoleh dari pengamatan dan pengukuran secara langsung di lapangan meliputi data tentang sistem pemesanan kamar hotel yang sedang berjalan sekarang, Jumlah kamar hotel, harga kamar hotel, dan fasilitas hotel.

2. Data Sekunder

Data sekunder adalah data yang diperoleh dari sumber tidak langsung di dapat dari blog/artikel melalui internet tentang ulasan mengenai fasilitas Hotel Kartika Kota Langsa.

Tahapan pengolahan yang akan digunakan untuk melakukan pengolahan data dalam penelitian yaitu sebagai berikut:

1. Merancang Diagram Konteks

Diagram Konteks merupakan diagram yang menggambarkan kondisi sistem yang ada baik input maupun output serta menyertakan terminator yang terlibat dalam penggunaan sistem. Diagram ini akan memberi gambaran tentang keseluruhan sistem. Diagram konteks berisi gambaran umum sistem yang akan dibuat. Dapat dikatakan bahwa diagram konteks berisi siapa saja yang menggunakan sistem, serta kepada siapa saja informasi yang harus dihasilkan sistem.

2. Merancang Aliran Proses

Menggunakan Data Flow

Diagram(DFD)

Aliran proses dari sebuah sistem informasi akan di rancang dengan Data Flow Diagram(DFD) yang akan memperlihatkan alur-alur sistem informasi pemesanan kamar hotel berbasis website (WEB).

3. Merancang hirarchy chart hirarchy chart dirancang untuk untuk mempersiapkan penggambarandata flow diagram(DFD) ke level-level yang lebih bawah lagi.

4. Merancang Flowchart

Flowchart dirancang untuk memperlihatkan proses aliran data sistem informasi yang akan dirancang sampai ke tahap output yang dihasilkan.

5. Merancang Database

Database di rancang untuk memperoleh semua informasi tentang sistem yang sudah dibangun dan saling berhubungan di dalam suatu organisasi hotel.

6. Desain Program 
Desain program diterjemahkan ke

dengan menggunakan bahasa dalam kode-kode yang terstruktur pemrograman yang sudah ditentukan.

\section{HASIL DAN PEMBAHASAN}

Hasil Penelitian

Data Jumlah Kamar Hotel, Harga Kamar, dan Jenis Kamar

Tabel 1 Data Jumlah Kamar Hotel, Harga Kamar dan Jenis Kamar

\begin{tabular}{|c|c|c|c|}
\hline N0 & JENIS KAMAR & JUMLAH & $\begin{array}{c}\text { HARGA / } \\
\text { KAMAR (Rp) }\end{array}$ \\
\hline 1 & SUITE ROOM & 2 UNIT & 800.000 \\
\hline 2 & SUPER DELUXE A & 2 UNIT & 700.000 \\
\hline 3 & SUPER DELUXE B & 5 UNIT & 650.000 \\
\hline 4 & DELUXE & 5 UNIT & 600.000 \\
\hline 5 & SUPERIOR & 10 UNIT & 450.000 \\
\hline 6 & STD A & 12 UNIT & 400.000 \\
\hline 7 & STD B & 6 UNIT & 350.000 \\
\hline 8 & STD C & $20 \mathrm{UNIT}$ & 300.000 \\
\hline 9 & EKONOMI & 8 UNIT & 150.000 \\
\hline \multicolumn{2}{|c|}{ JUMLAH KAMAR } & 70 UNIT & \\
\hline
\end{tabular}

Sumber: Hotel Kartika

\section{Data Fasilitas Hotel}

Tabel 2 Database Fasilitas Hotel

\begin{tabular}{|c|c|}
\hline NO & Keterangan \\
\hline 1 & Restoran \\
\hline 2 & Loundry \\
\hline 3 & Aula_Pertemuan \\
\hline 4 & Musholla \\
\hline 5 & Ruang_tamu \\
\hline 6 & Wifi Free \\
\hline 7 & Tempat Parkir \\
\hline
\end{tabular}

\section{Rancangan Konteks Diagram}

Dibawah ini adalah gambar konteks diagram yang mengambarkan alur proses sistem informasi pemesanan kamar hotel yang berbasis website. 


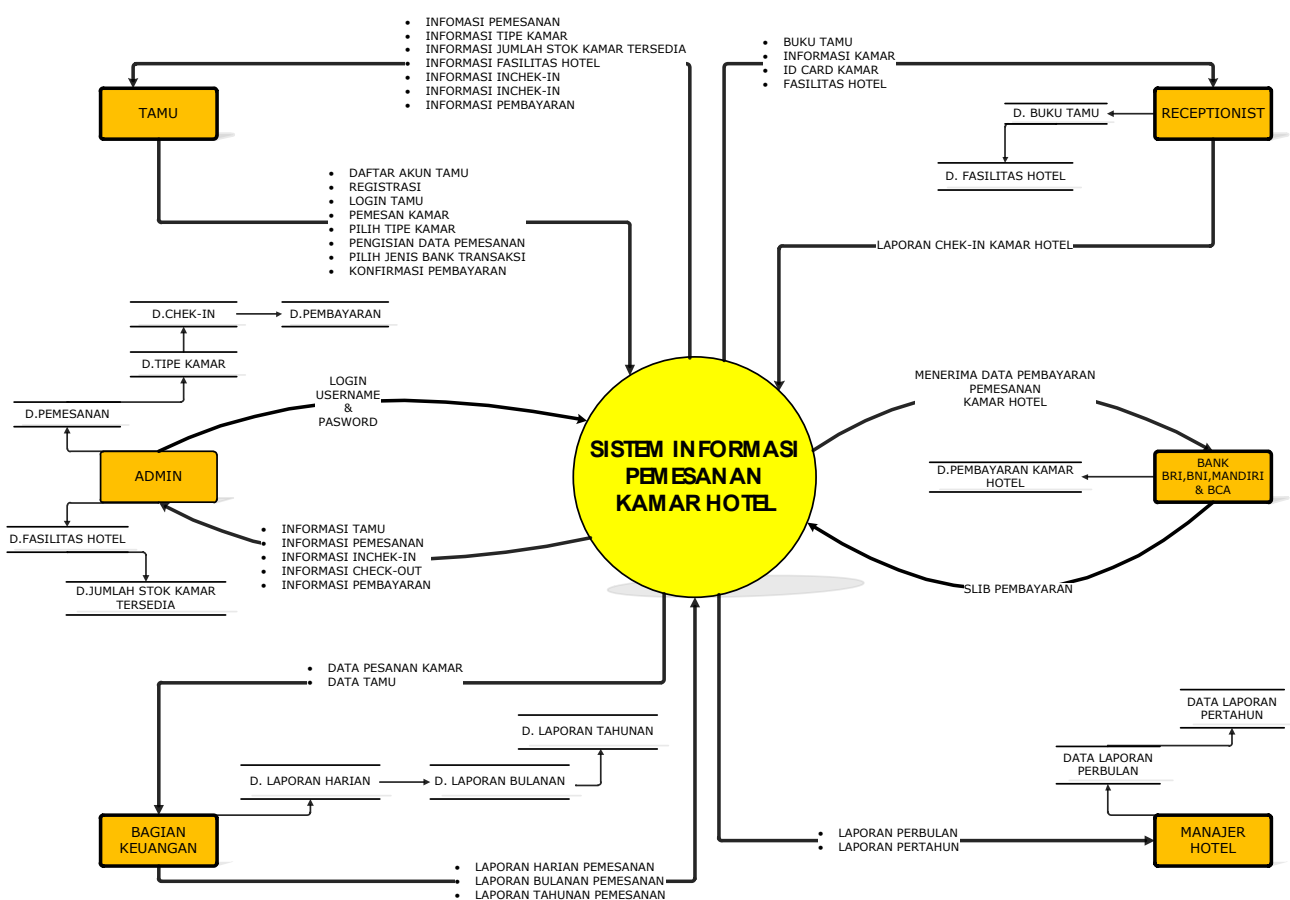

Gambar 2 Konteks Diagram

\section{Rancangan Hierarchy Chart}

Dari diagram konteks diatas kemudian dibuat hirarchy chart guna untuk mempersiapkan penggambaran data flow diagram (DFD) ke level-level yang lebih bawah lagi. Untuk sistem informasi pemesanan kamar hotel yang berbasis website (WEB)

\section{LEVELO}
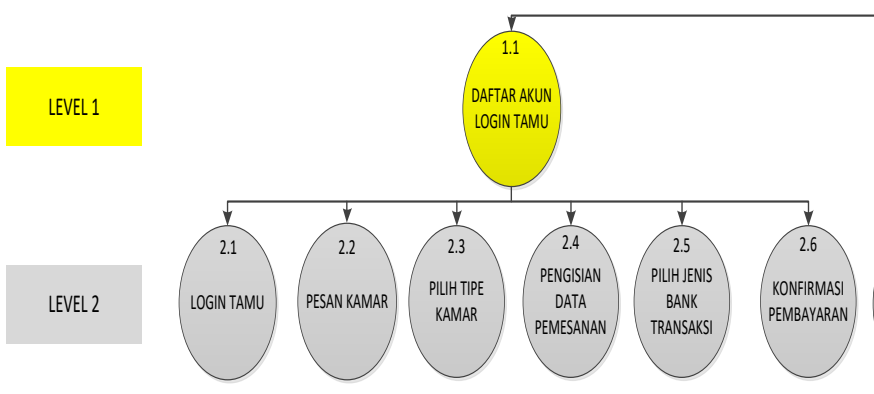

\section{Gambar 3. Hierarchy Chart}

Gambar 3 Hierarchy Chartdiatas menjelaskan level-level proses dari tahap ke tahap dalam sistem informasi pemesanan kamar hotel berbasis website ini. Dalam Hirarchy Chartdiatas terdapat 4 level yaitu:

Level 1 adalah proses daftar akun login tamu, login admin, check-in hotel, cetak struk pemesanan harian. Level 2 adalah proses login tamu, pesan kamar, pilih tipe kamar, pengisian data pemesanan, pilih jenis bank transaksi, konfirmasipembayaran,konfirmasi pemesanan, input data tamu, id card kamar hotel, pengolahan laporan harian,pengolahan

laporan bulanan, dan pengolahan laporan tahunan. 


\section{FlowChart Pemesanan Kamar Hotel}

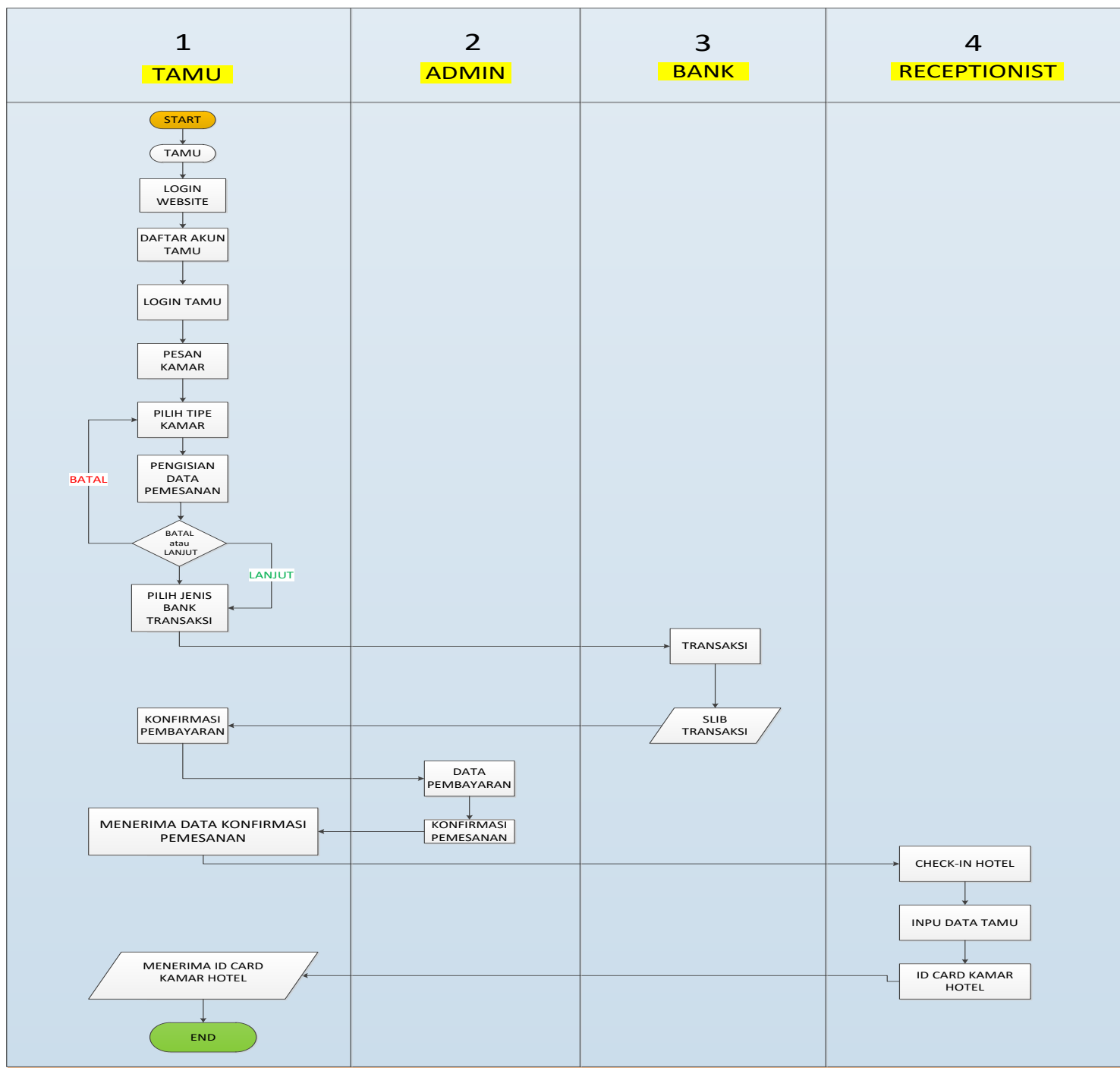

Gambar 4. Flowchart Pemesanan Kamar Hotel

Gambar 4 adalah bentuk aliran flowchart proses pemesanan kamar hotel sampai proses chek-in hotel.

\section{Database Sistem Informasi Hotel}

Tabel 3. Database Admin

\begin{tabular}{|c|l|l|}
\hline \multicolumn{3}{|c|}{ Tabel Database Admin } \\
\hline NO & \multicolumn{1}{|c|}{ Atribut } & \multicolumn{1}{c|}{ Keterangan } \\
\hline 1 & Username & Admin \\
\hline 2 & Password & Hotel_Kartika \\
\hline
\end{tabular}


Tabel 4. Database Tamu

\begin{tabular}{|c|l|c|}
\hline \multicolumn{2}{|c|}{ Tabel Database Tamu } \\
\hline NO & Atribut & Keterangan \\
\hline 1 & Nama & Muliadi \\
\hline 2 & No_Hp & 85373279448 \\
\hline 3 & Alamat & Langsa \\
\hline 4 & Email & mteuku303@gmail.com \\
\hline
\end{tabular}

Sumber: Pengolahan Data (Hotel Kartika)
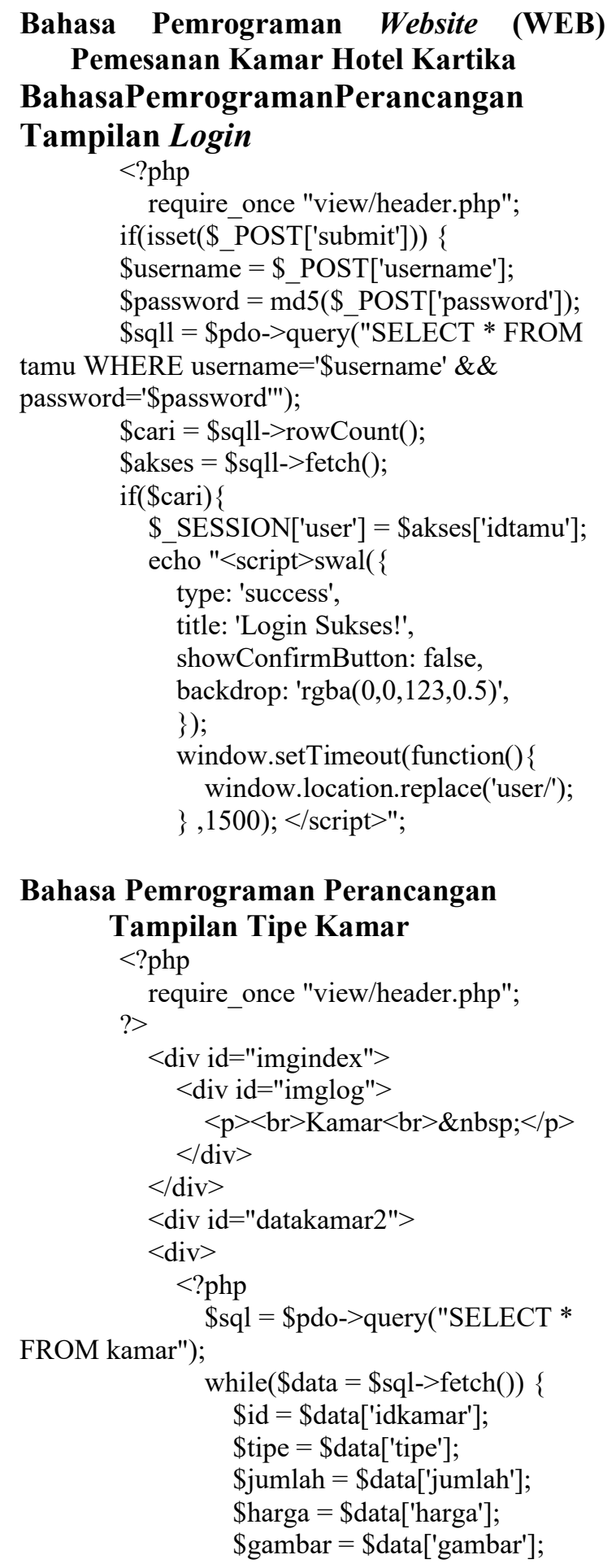

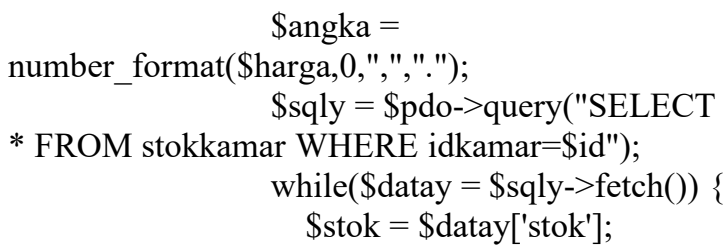

Tampilan Hasil Rancangan Program Aplikasi Website (WEB) Pemesanan Kamar Hotel Kartika Kota langsa.

Tampilan aplikasi website (WEB) Hotel Kartika terdapat 2 perancangan yaitu tampilan untuk admin hotel dan tampilan untuk pelanggan (tamu hotel) tampilan untuk admin hotel terdiri dari 12 tampilan dan untuk tampilan pelanggan (tamu hotel) terdiri dari 14 tampilan.

Tampilan halaman untuk admin hotel terdiri dari 12 yaitu:

1. Halaman login admin

2. Halaman beranda admin

3. Halaman tampilan input data kamar

4. Halaman tampilan data kamar

5. Halaman tampilan edit stok kamar

6. Halaman tampilan daftar usser masuk

7. Halaman tampilan data pembayaran

8. Halaman tampilan konfirmasi pemesanan

9. Halaman tampilan transaksi sukses

10. Halaman tampilan transaksi batal

11. Halaman tampilan kontak hotel

12. Halaman tampilan keluar

Tampilan halaman pelanggan (tamu hotel) terdiri dari 14 tampilan yaitu:

1. Halaman tampilan daftar usser dan login website

2. Halaman tampilan registrasi tamu

3. Halaman tampilan login tamu

4. Halaman tampilan pesan kamar

5. Halaman tampilan data jenis kamar

6. Halaman tampilan pemesanan kamar 
7. Halaman tampilan jenis rekening bank

8. Halaman tampilan data pemesanan

9. Halaman tampilan konfirmasi pemesanan

10. halaman tampilan transaksi batal

11. halaman tampilan transaksi berhasil

12. halaman tampilan fasilitas hotel

13. halaman tampilan kontak admin hotel

14. halaman tampilan keluar akun Di bawah ini adalah tampilan aplikasi Website (WEB) pemesanan kamar Hotel Kartika Kota Langsa yang sudah di rancang.

\section{Tampilan Website (WEB) Halaman Admin}

Tampilan websitehalamanadmin adalah tempat website yang akan di masuki oleh adminuntuk mengelola website hotel, dibawah ini adalah tampilan halaman website untuk halaman admin hotel.

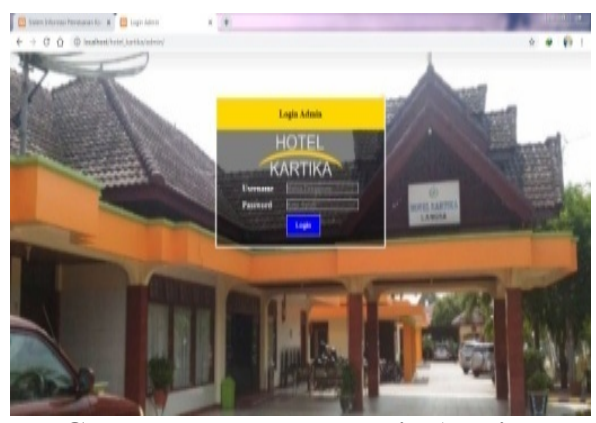

Gambar 5. Halaman Login Admin

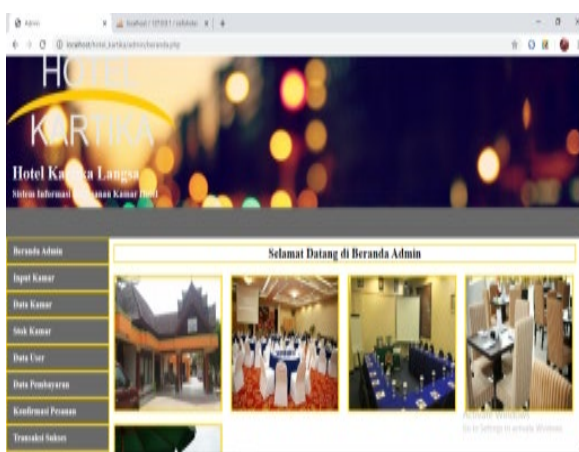

Gambar 6. Halaman Beranda Admin

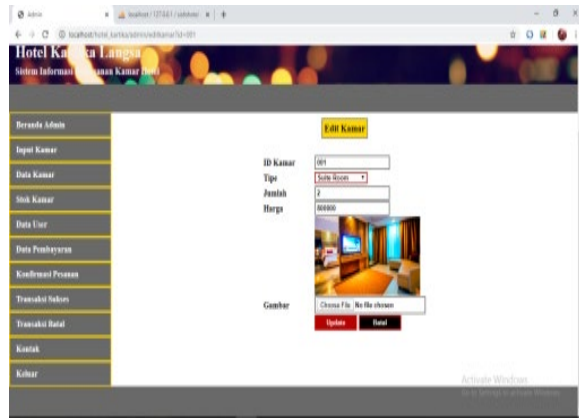

Gambar 7. Halaman Tampilan Input Data Kamar

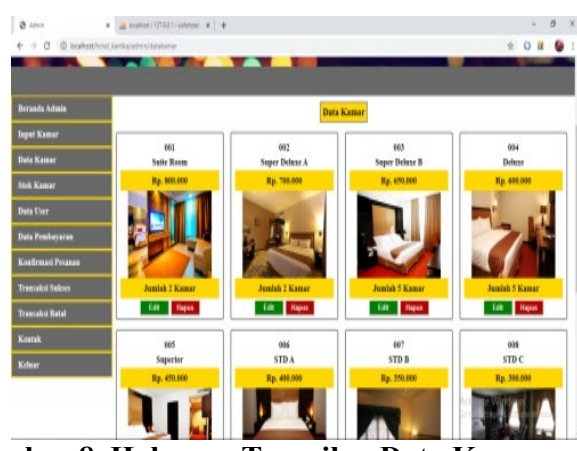

Gambar 8. Halaman Tampilan Data Kamar

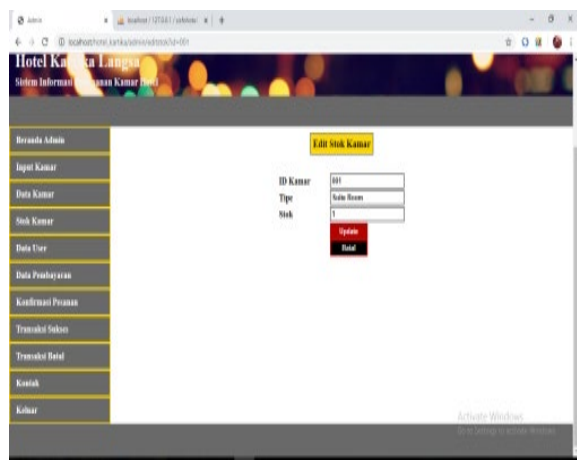

Gambar 9. Halaman Tampilan Edit Stok Kamar

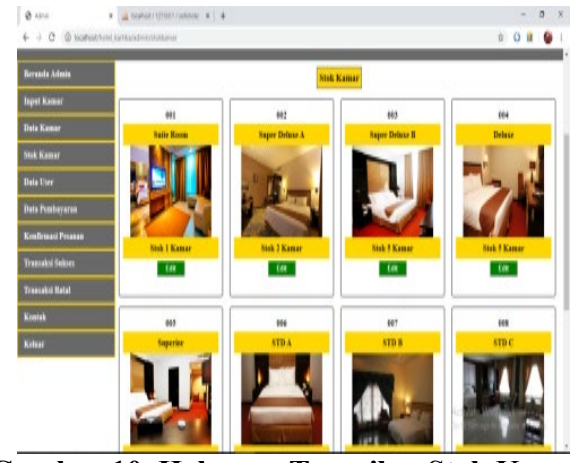

Gambar 10. Halaman Tampilan Stok Kamar

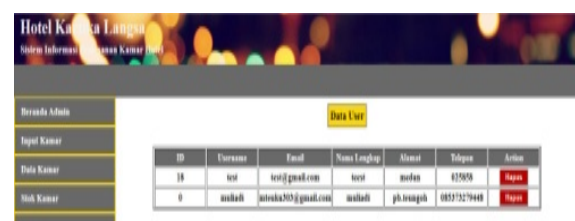

Gambar 11. Halaman Tampilan Daftar Usser Masuk 


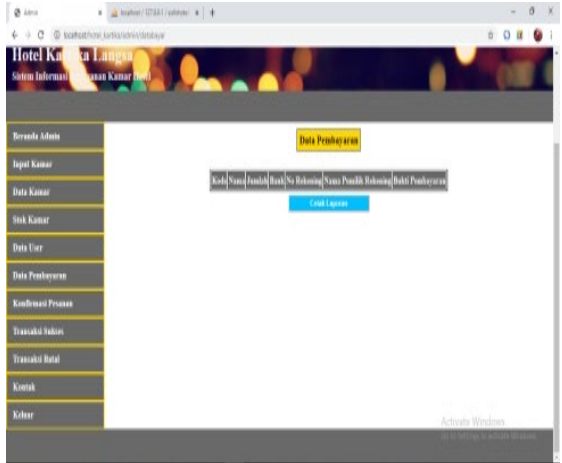

Gambar 12. Halaman Tampilan Data Pembayaran

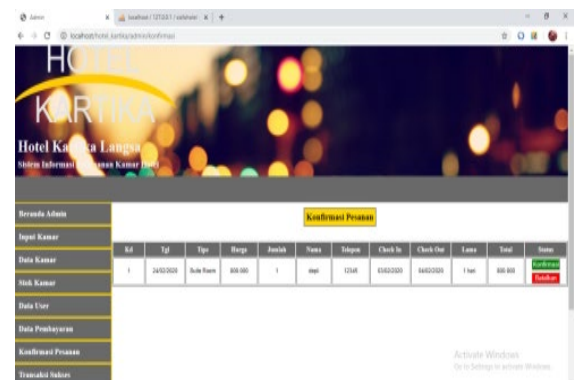

Gambar 13. Halaman Tampilan Konfirmasi Pemesanan

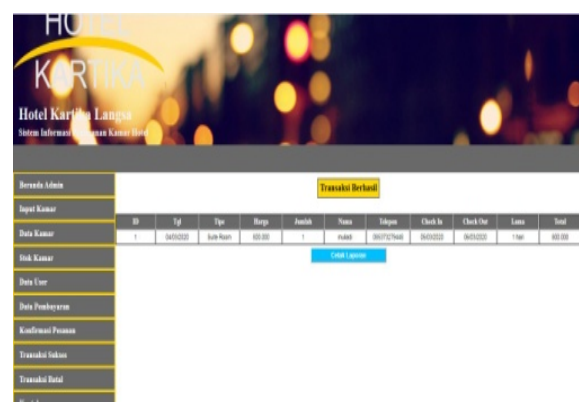

Gambar 14. Halaman Tampilan Transaksi Sukses

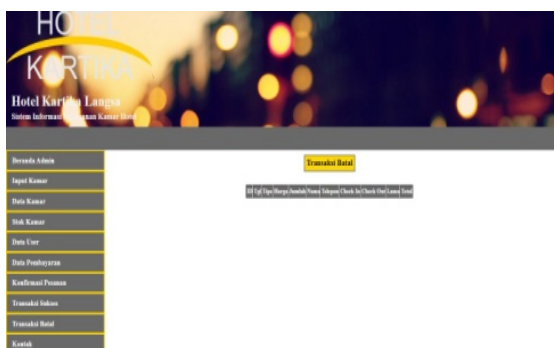

Gambar 15. Halaman Tampilan Transaksi Batal

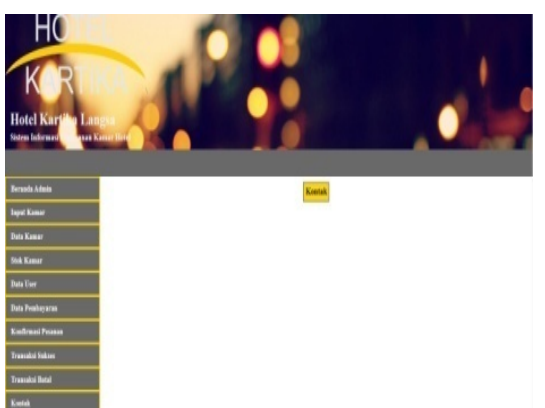

Gambar 16. Halaman Tampilan Kontak Hotel

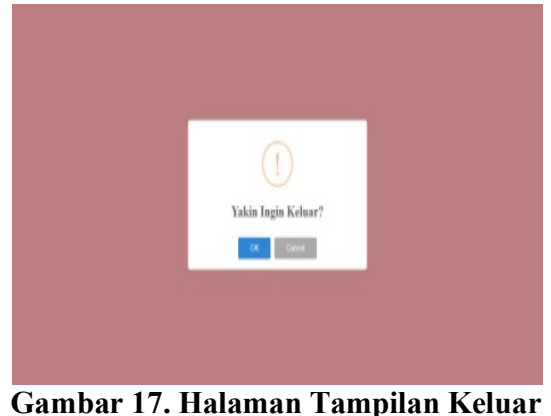

Tampilan Website (WEB)Halaman Pengunjung Tamu Hotel.

Tampilan website pengunjung tamu adalah tempat website yang akan di masuki oleh tamu pada saat memesan kamar hotel, dibawah ini adalah tampilan halaman website untuk halaman pengunjung tamu hotel.

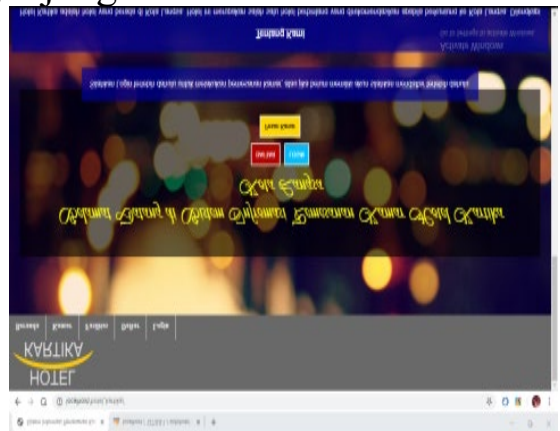

Gambar 18. Halaman Tampilan Daftar Usser dan Login Website

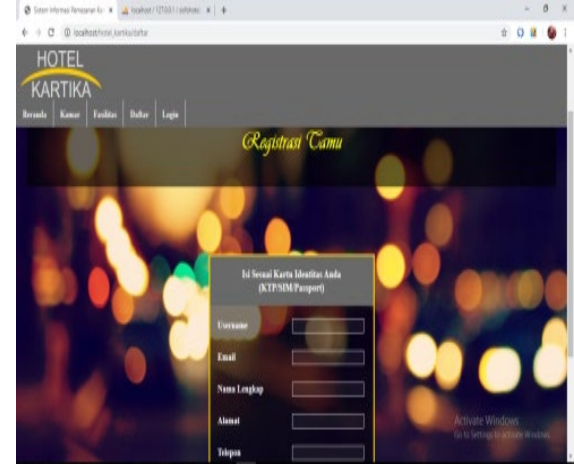

Gambar 19. Halaman Tampilan Registrasi Tamu

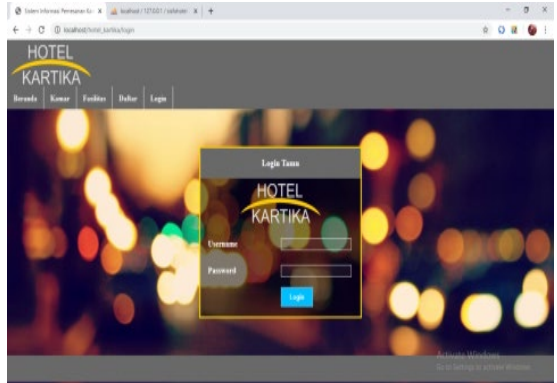

Gambar 20. Halaman Tampilan Login Tamu 


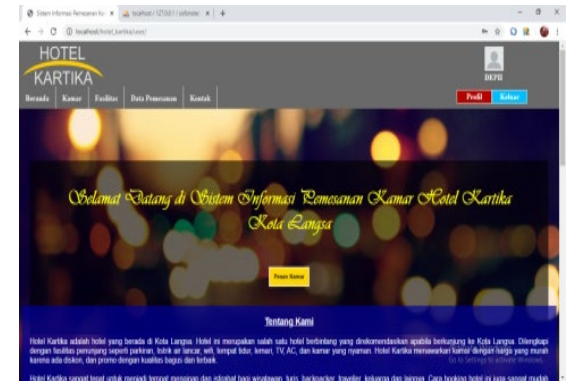

Gambar 21. Halaman Tampilan Pesan Kamar

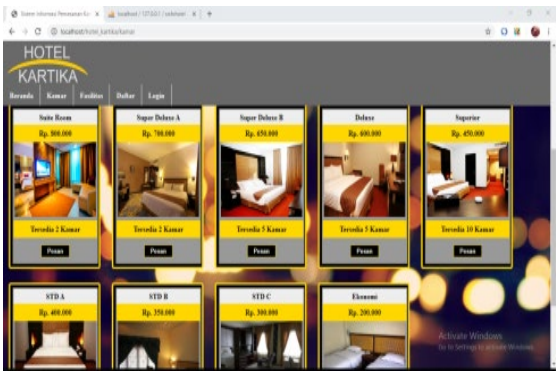

Gambar 22. Halaman Tampilan Data Jenis Kamar

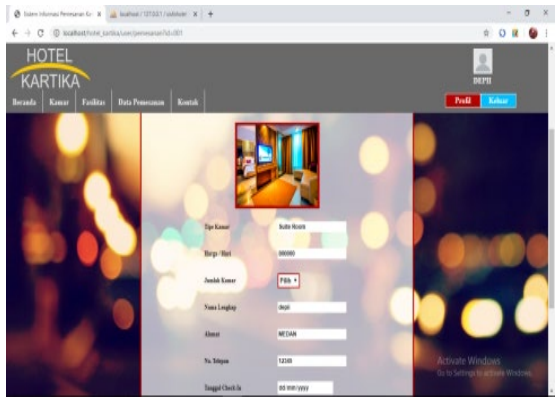

Gambar 23. Halaman Tampilan Pemesanan Kamar

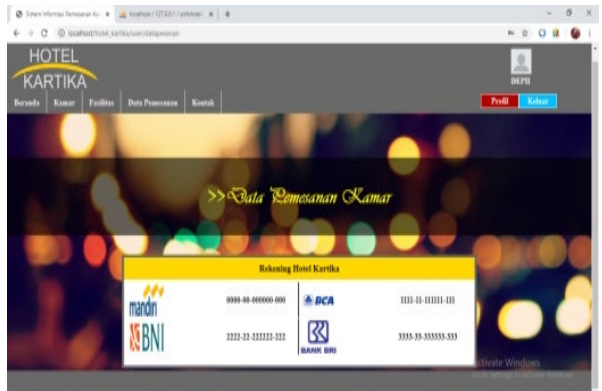

Gambar 24. Halaman Tampilan Jenis Rekening bank

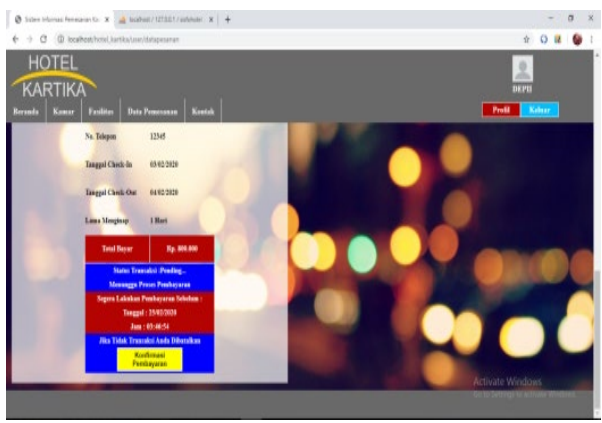

Gambar 25. Halaman Tampilan Data Pemesanan

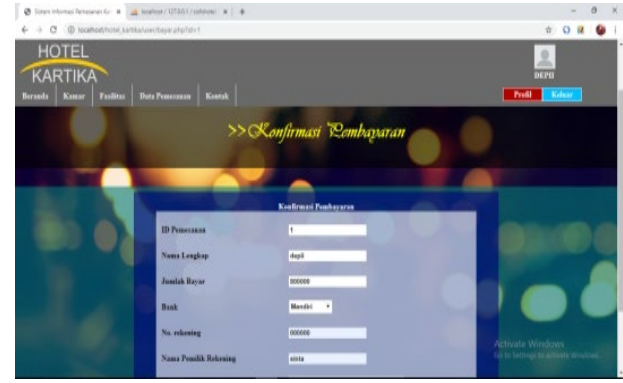

Gambar 26. Halaman Tampilan Konfirmasi Pembayaran

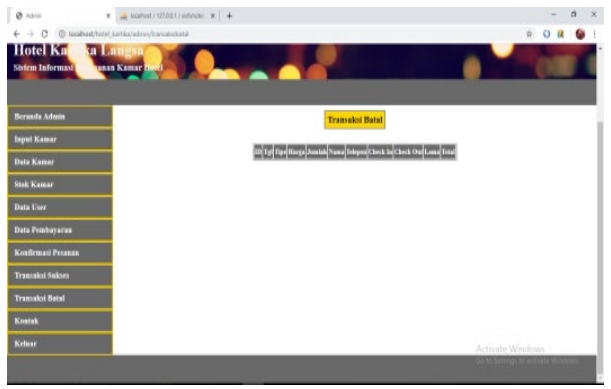

Gambar 27. Halaman Tampilan Transaksi Batal

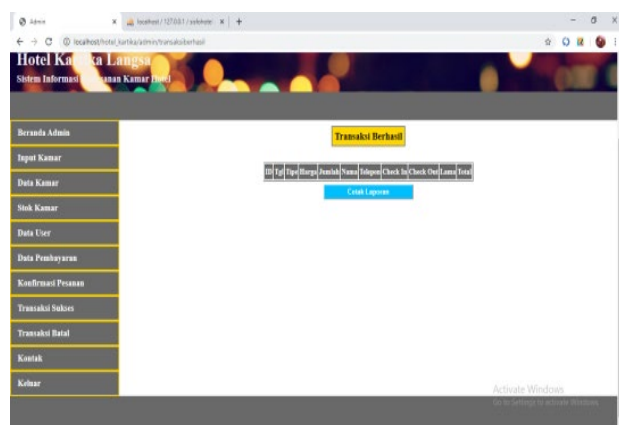

Gambar 28. Halaman Tampilan Transaksi Berhasil

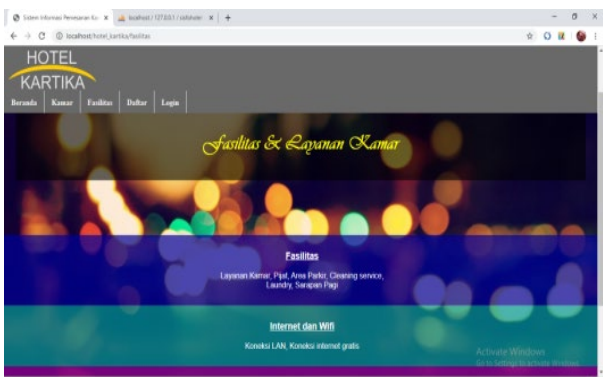

Gambar 29. Halaman Tampilan Fasilitas Hotel

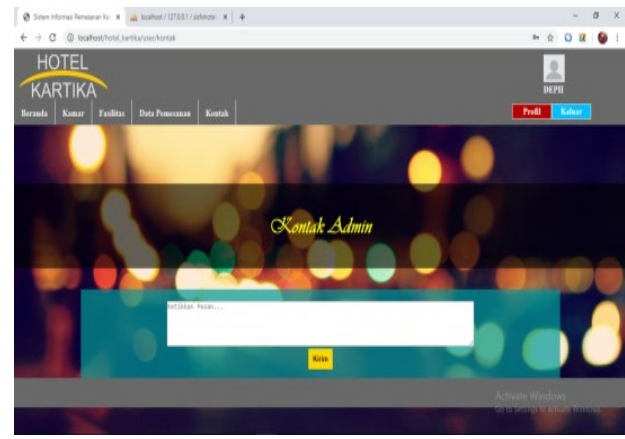

Gambar 30. Halaman Tampilan Kontak AdminHote 


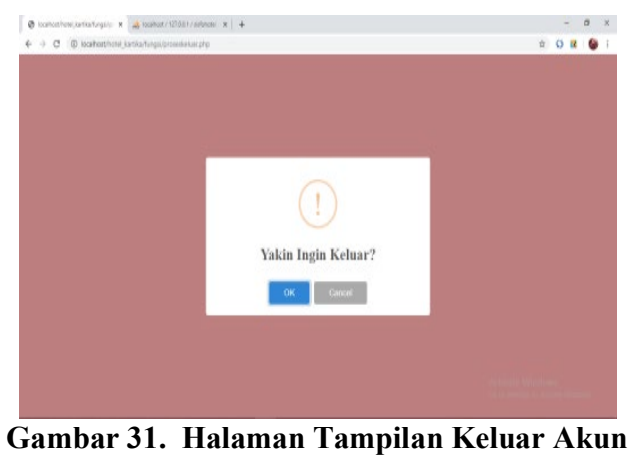

4. KESIMPULAN

Rancangan sistem informasi pemesanan kamar Hotel Kartika yang sudah dirancang terdapat beberapa itemitem yang bisa di lihat didalam website hotel-kartika.epizy.com yaitu terdapat data fasilitas hotel terdiri dari Restoran, Loundry, Aula pertemuan, Musholla, Ruang tamu, Wifi free, Tempat Parkir. Data jenis kamar hotel terdiri dari Suite Room , Super Deluxe A, Super Deluxe B , Deluxe, Superior, Std A , Std B , Std C dan Ekonomi dan untuk data harga kamar hotel terdiri dari 150 ribu sampai dengan 800 ribu.

Rancangan sistem informasi yang sudah dirancang juga menampilkan halaman admin untuk pengelolaan database website hotel yang telah di rancang. Pelanggan hotel dalam memesan kamar di haruskan untuk mendaftar akun agar dapat memesan kamar hotel sesuai pilihan yang di inginkan yang sudah tersedia di website hotel.

Sistem informasi pemesanan kamar hotel yang berbasis website (WEB) memudahkan pelanggan untuk mengetahui informasi hotel dan sistem pemesanan kamar pada Hotel Kartika. Situs website pemesanan kamar Hotel Kartika bisa di kunjungi di website dengan nama domain hotel-kartika.epizy.com

\subsection{Saran}

Adapun saran yang diberikan untuk sistem informasi pemesanan kamar hotel berbasis website (WEB) ini adalah sebagai berikut :

1. Sistem informasi pemesanan kamar hotel berbasis website ini masih banyak terdapat kekurangan sehingga masih belum sempurna dalam penggunaannya, untuk itu diharapkan adanya pengembangan yang dilakukan untuk dapat lebih memperbaiki kekurangan terdapat pada program aplikasi sistem informasi ini.

2. Supaya sistem berfungsi dengan baik maka disarankan kepada pihak Hotel Kartika Kota Langsa agar selalu melakukan pemeliharaan terhadap sistem informasi pemesanan kamar hotel ini dan segera memperbaiki nya apabila terjadinya kesalahan atau error.

\section{DAFTAR PUSTAKA}

Astuti, Iftadi (2016) Analisis dan Perancangan Sistem Kerja, Yogyakarta: Deepublish Desember 2016

Jogiyanto, HM. (2001)AnalisisPerancangan Sistem Informasi. Andi Offset.Yogyakarta.

Kusumawardani, Wardati (2014) Analisis Dan Perancangan Sistem Informasi

HotelGraha Prima Pacitan Journal Speed - $\quad$ Sentra PenelitianEngineeringdanEdukasi Volume 6 No 3 - 2014 - ijns.org.

Andriani,M. and Subhan (2016) 'Perancangan Peralatan Secara ErgonomiUntuk Meminimalkan Kelelahan Di PabrikKerupuk, TI-014, Seminar Nasional Sains dan Teknologi 2016Fakultas Teknik Universitas Muhammadiyah Jakarta , 8 November 2016

Muslihudin,dkk. (2016) Analisis dan Perancangan Sistem Informasi Menggunakan Model Terstruktur dan UML, Yogyakarta: Andi

Sutedjo Budi, (2006), Perencanaan \& PembangunanSistemInformasi.Yogya karta: Andi

Surono (2014) Data Flow Diagram (DFD) Pada Apotek Candra Kota Jambi.Jurnal Ilmiah Universitas Batang hari Jambi Vol.14 No.4 Tahun 2014

Syifaun. (2003)Grafika Computer Borland $\mathrm{C}++$ Builder Professional. Yogyakarta: Graha Ilmu

Prasetyo (2015) Sistem Informasi Manajemen Hotel Arrahman Tembilahan Berbasis Web (Online) Pada Hotel Arrahman Tembilahan. Jurnal Sistemasi, Volume 
4, Nomor 3, September $2015: 25-34$

Parahita, dkk. (2017) Sistem Informasi Perhotelan Berbasis Web Service : Studi Kasus Di Pulau Lombok (Hotel Information System Based on Web Service - Case Study: Lombok Island). J-COSINE, Vol. 1, No. 1, Desember 2017 